\title{
Fostering Science Education in the Developing Countries
}

\author{
James C. White II \\ Rhodes College, Department of Physics, Memphis, Tennessee 38112 \\ USA \\ E-mail: jwhite@rhodes.edu
}

\section{Introduction}

Considerable attention is paid to how we teach science and to how our students learn it. Even though similar questions are asked by scientists and science teachers in all countries, one finds that resources available for science education in developing countries are often scarce.

Resources for science in general are often quite limited in countries less wealthy than those of, say, North America or the European Union. Leaving aside for the moment those resources for scientific research-equipment, communication infrastructure (journals, internet access, etc.), and opportunity for collaboration with scientists outside the country - one confronts the needs of a country for the development and advancement of its science education system: equipment, communication infrastructure (textbooks, internet access, etc.), and collaboration with science teachers inside and outside the country. That the needs of the scientific enterprise and those of the education enterprise are so similar is not surprising, given that good science can enrich teaching and engaging teaching can compel one, student or teacher alike, to ask new questions and, hence, to conduct new, enriched science.

\section{Education Needs}

To many policy makers in wealthy and comparatively poor countries alike, enriched science education means increased funding, which, in the zero-sum game of politics, means less money for other national needs. This assumption need not be true, however.

\subsection{Equipment}

If one walks into a physical science classroom in the United States, one will discover lab benches scattered with instruments and shelves filled with scientific apparatus. The same is not typically true for a science classroom or lab space in a developing country (DC).

Despite the seemingly endemic electronic devices that whirl and buzz and spit out data to an associated computer, teachers are again realizing that some of the most effective demonstrations and laboratory experiences for our students come from simple, inexpensive sources. As examples, one can use a burning tea bag to demonstrate convection or a falling feather to investigate air resistance. 
Consider that once the student leaves the classroom, she can locate the same materials to reproduce the experiment inexpensively for herself.

Rather than considering how best for us to fund equipment purchases for science classrooms in DCs, we should use "equipment" available locally in the country-teabags, bits of twine, melons, etc. All we need do is guide teachers there in its use and in how interpretation of results can enrich the classroom experience for their students.

\subsection{Communication}

Educational research and common sense suggest that effective communication is a critical element in student learning-communication between the teacher and student, between students, and even between teachers as they discuss what works and does not work in their classrooms. The internet is clearly an effective means of bringing teachers and pupils together in non-traditional means-as example, having electronic office hours after the school is closed for the daybut one can not assume that the relatively easy internet access one has in, say, the United States, is available in DCs.

For this reason, standard means of communication, verbal and written, must still be relied upon for the majority of learning in the developing world. Textbooks are often the main source of information, too. Recognizing the importance of textbooks, particularly in DCs, a segment of the IAU's "Teaching Astronomy for Development" Program Group (Commission 46) worked in 19992001 with Vietnamese astronomers and educators to write and then publish a new astrophysics textbook.

The first Vietnamese textbook to contain color illustrations, Astrophysics was written by four Vietnamese astronomers and one American astronomer. Both Vietnamese and English are used in the text, with Vietnamese language on left pages facing English translations on the right. Such a design presents students with the science and also provides them with opportunity to refine their English language skills and improve their English science vocabulary.

\subsection{Collaboration}

Discovering what does and does not work in someone else's classroom can save one time and effort. Yet fostering communication among scientists in DCs and with their colleagues in wealthier countries is difficult: technological, cultural, and language barriers stand ready to aggravate, if not prevent, such dialogue. The IAU's Commission 46 facilitates better communication through various activities, and the "Teaching Astronomy for Development" Program Group is charged explicitly with offering assistance, advice, and guidance to science educators in developing countries. From visits to the countries by foreign scientists to assisting financially select students from DCs with their graduate educations abroad, TAD seeks to minimize the loneliness a scientist or science educator feels in a country with little resources for education and science. Indeed, by offering advice or services the host country believes it needs, TAD, and the associated Program Groups in Commission 46, attempts to connect each scientist and science educator with the rest of the world-bringing the individual, and his or her students, into the global scientific endeavor. 